\title{
Molecular regulation of epithelial-to-mesenchymal transition in tumorigenesis (Review)
}

\author{
HENRIETA ŠKOVIEROVÁ ${ }^{1}$, TERÉZIA OKAJČEKOVÁ ${ }^{1,2}$, JÁN STRNÁDEL ${ }^{1}$, \\ EVA VIDOMANOVÁ ${ }^{1}$ and ERIKA HALAŠOVÁ ${ }^{1,3}$
}

\author{
${ }^{1}$ Biomedical Center Martin, Department of Molecular Medicine; Departments of ${ }^{2}$ Medical Biochemistry and ${ }^{3}$ Medical \\ Biology, Jessenius Faculty of Medicine in Martin, Comenius University in Bratislava, Martin 03601, Slovakia
}

Received May 29, 2017; Accepted November 23, 2017

DOI: $10.3892 /$ ijmm.2017.3320

\begin{abstract}
Numerous studies over the past two decades have focused on the epithelial-to-mesenchymal transition (EMT) and its role in the development of metastasis. Certain studies highlighted the importance of EMT in the dissemination of tumor cells and metastasis of epithelium-derived carcinomas. Tumor metastasis is a multistep process during which tumor cells change their morphology, and start to migrate and invade distant sites. The present review discusses the current understanding of the molecular mechanisms contributing to EMT in embryogenesis, fibrosis and tumorigenesis. Additionally, the signaling pathways that initiate EMT through transcriptional factors responsible for the activation and suppression of various genes associated with cancer cell migration were investigated. Furthermore, the important role of the epigenetic modifications that regulate EMT and the reverse process,
\end{abstract}

Correspondence to: Dr Eva Vidomanová, Biomedical Center Martin, Department of Molecular Medicine, Jessenius Faculty of Medicine in Martin, Comenius University in Bratislava, Malá Hora 4D, Martin 03601, Slovakia

E-mail: evablahovcova@gmail.com

Abbreviations: CTCs, circulating tumor cells; DNMT, DNA methyltransferase; DTCs, disseminated tumor cells; ECM, extracellular matrix; E-cadherin, epithelial cadherin; EMT, epithelial-to-mesenchymal transition; EpCAM, epithelial cellular adhesion molecule; ESRP1, epithelial splicing regulatory protein 1; HDAC, histone deacetylase; HIF, hypoxia-inducible factor; ID, inhibitor of differentiation proteins; lncRNA, long non-coding RNA; MET, mesenchymal-to-epithelial transition; MMP, matrix metalloproteinase; $\mathrm{N}$-cadherin, neural cadherin; NF- $\mathrm{kB}$, nuclear factor $\kappa$-light-chain-enhancer of activated B cells; NK cells, natural killer cells; Notch, neurogenic locus notch homolog protein; SNAIL1, Snail family zinc 1 finger; TIAM1, T-lymphoma invasion and metastasis inducing protein 1 ; $\mathrm{TF}$, transcriptional factor; $\mathrm{T} \beta \mathrm{R}$, transforming growth factor $\beta$ receptor; TGF- $\beta$, transforming growth factor- $\beta$; TNF- $\alpha$, tumor necrosis factor- $\alpha$; TWIST1, Twist family BHLH transcriptional factor 1; ZEB, zinc finger E-box binding homeobox

Key words: cancer, circulating tumor cells, circulating tumor cell clusters, dormancy, metastasis, microRNA mesenchymal-to-epithelial transition (MET) are discussed. MicroRNAs are key regulators of various intracellular processes and current knowledge of EMT has significantly improved due to microRNA characterization. Their effect on signaling pathways and the ensuing events that occur during EMT at the molecular level is becoming increasingly recognized. The current review also highlights the role of circulating tumor cells (CTCs) and CTC clusters, and their ability to form metastases. In addition, the biological properties of different types of circulating cells based on their tumor-forming potential are compared.

\section{Contents}

1. Introduction

2. EMT in embryogenesis

3. EMT in chronic diseases

4. EMT in tumorigenesis

5. Molecular mechanisms of EMT regulation

6. Different types of metastatic cancer cells

7. Methods for CTC and CTC cluster detection

8. Future perspectives

\section{Introduction}

Epithelial-to-mesenchymal transition (EMT) is an evolutionarily conserved process that regulates the expression levels of various genes in epithelial cells that assume the mesenchymal phenotype. During the early phase of human development, EMT is involved in stem cell plasticity and morphogenesis necessary for proper gastrulation and organ development $(1,2)$. In the adult organism, tissue conservation may be regulated via EMT [and the reverse process, mesenchymal-to-epithelial transition (MET)], and may lead to tissue reconstruction and the restoration of cell homeostasis following inflammatory insults. It is known that the EMT/MET process is important in chronic inflammatory and degenerative diseases (for example, organ fibrosis), which may result in organ insufficiency followed by organ failure (3). EMT under physiological conditions is similar to pathological EMT, in that it is controlled by similar regulators, signaling pathways and effectors. 
During tumor development, various types of cell, such as circulating tumor cells (CTCs) and CTC clusters, may be observed in the patient's bloodstream. In addition, another type of cell, disseminated tumor cells (DTCs), which are present in the bone marrow, are important during metastasis development (4). CTCs and CTC clusters are released from primary tumors after significant changes in cell morphology due to EMT (5). It has been demonstrated that EMT is crucial in the development of metastasis, as follows: i) Changes in cell polarity from apical-basal to antero-posterior and loss of adherens junctions; ii) changes from the epithelial to the mesenchymal phenotype; and, iii) higher mobility and invasiveness of cancer cells (6). One of the most common characteristics of epithelial cells is the strong cell-cell adhesion integrity via various components, such as E-cadherin and cytokeratins, with desmosomes and adherens, and tight and gap junctions. Furthermore, the activity of matrix metalloproteinases (MMPs) is highly increased during EMT. These enzymes are responsible for extracellular matrix (ECM) degradation and, therefore, for increased mobility of mesenchymal-like cells, which is necessary for invasion and metastasis (7). CTCs and CTC clusters represent an attractive alternative to tissue biopsy of metastatic lesions, due to the fact that they may be non-invasively obtained. Current research on CTCs and CTC clusters may lead to the discovery of novel potential diagnostic procedures that will improve knowledge of the molecular mechanisms and perseverance of tumor cells in the bloodstream, during and following drug therapy. CTC clusters are aggregates consisting of various types of cell, such as tumor, stroma and immune cells, as well as platelets. This combination of cells is referred to as a microembolus (8). The niche, the inner microenvironment of CTC clusters, may protect them from lysis in the bloodstream by minimizing immune attacks and shear stress, and also facilitate cells by promoting colonization (9).

Due to the complexity of the EMT process, special transcription factors and signaling pathways are activated in epithelial cells to regulate all the molecular and morphological changes. These include the Snail family zinc finger transcriptional factors (SNAIL), Twist family BHLH transcriptional factor (TWIST) and zinc finger E-box binding homeobox (ZEB) factors, and the transforming growth factor (TGF) $-\beta$ and $W n t / \beta$-catenin signaling pathways, which are highly conserved among species (10). Notably, cancer cells must avoid anoikis before escaping from the primary tumor. This type of programmed cell death is observed in anchorage-dependent cells, which are detached from the ECM $(11,12)$. In addition, EMT is regulated by epigenetic mechanisms, such as DNA methylation, histone methylation and acetylation, and by microRNA binding (10). Epigenetic regulation is particularly important due to the reversibility of EMT and the flexibility of tumor cells to react to different internal and external stimuli. Taken together, currently available information may provide a complete understanding of the mechanisms underlying EMT, and may indicate methods to develop novel drugs that are able to target this transition process during tumorigenesis. Therefore, a review of the present knowledge of EMT in human cancer was prepared, focusing on the following: i) Its regulation via the TGF- $\beta$ signaling pathway, epigenetic modifications and microRNAs; and ii) the biological properties of different types of CTCs and their role in tumorigenesis.

\section{EMT in embryogenesis}

EMT and MET are crucial during embryogenesis, as they contribute to the induction of implantation and gastrulation $(13,14)$.

Epithelial cells form a sheet with cells connected by specific junctions and adherent molecules, such as desmosomes, and tight, gap or adherens junctions. The latter are important for constructing and assembling lateral intercellular connections in the sheet of cells in the epithelium (15). Furthermore, epithelial cells with apical-basal orientation are connected to the basement membrane. Under physiological conditions, the association with the basement membrane allows only lateral movement of epithelial cells (14). Therefore, maintaining their organization within the epithelium prevents cell admittance into the ECM.

The majority of mesenchymal cells of metazoans are derived from the primitive epithelium during early embryogenesis. Unlike epithelial cells, mesenchymal cells display a front-rear polarity and very rarely exhibit tight cell-cell connections (16). Furthermore, mesenchymal cells migrate through the ECM as a single cell. Although epithelial, as well as mesenchymal, cells have long been characterized in the developing embryo, EMT was only identified as a cellular process in the 1980s. Greenburg and Hay (17) performed a set of in vitro experiments that focused on the culture of epithelial cells in 3D gels. The authors demonstrated that these cells lost their apical-basal polarity and assumed a mesenchymal-like phenotype. Furthermore, the presence of pseudopodia and filopodia in mesenchymal cells supported the hypothesis that epithelial cells transition to the mesenchymal phenotype via the EMT process. Multiple steps are involved in activating EMT during embryogenesis to enable the conversion of epithelial into mesenchymal cells (14).

It is necessary to study the EMT/MET process during embryogenesis, as the derived knowledge may be useful for elucidating pathological processes, such as chronic diseases and tumor development. Furthermore, this knowledge may be helpful for the development of novel cancer therapeutic agents.

\section{EMT in chronic diseases}

Physiological regeneration shares the same molecular principle of EMT/MET as embryonic development. EMT/MET are important during chronic conditions caused by inflammation and upregulated regeneration.

In fibrotic tissues, myofibroblasts produce an excessive quantity of collagen. This protein may compromise organ function and lead to its failure. It has been hypothesized that fibrosis occurs via the activation of interstitial fibroblasts, which may be transformed to myofibroblasts during pathological processes. It was experimentally demonstrated that certain myofibroblasts were originally epithelial cells that underwent EMT (18-20).

Transition of endothelial cells into mesenchymal-like cells was also observed in renal and cardiac fibrosis $(21,22)$. Notably, mesothelial cells may transform into mesenchymal cells in 
patients who undergo ambulant dialysis, who may develop peritoneal fibrosis, a process involving the mitogen-activated protein kinases (MAPK) signaling pathway and SNAIL activation (23). In addition, EMT may occur in the epithelial cells of the lens, where it contributes to the development of capsular opacity following cataract surgery. It was demonstrated that SNAIL activation via TGF- $\beta$ in the adult kidney may be implicated in the induction of renal fibrosis followed by renal failure (24). Elevated SNAIL expression levels have been identified in fibrotic kidneys of patients subjected to nephrectomy. Based on this observation, higher expression levels of the TGF- $\beta$ protein may be either a part of the physiological reaction to an insult, or a pathological response. As SNAIL transduces the detrimental effect of TGF- $\beta$, inhibition of SNAIL may be a preferable alternative to treating kidney disease, as that would preserve the beneficial effect on TGF- $\beta$ secretion (18). Initially demonstrated in differentiated renal ducts and tubules, it is obvious that cells of the endothelium, epithelium and lens, cardiomyocytes and hepatocytes may be transformed via EMT, leading to the progression of tissue fibrosis $(21,22)$.

These observations may be useful for future therapeutic methods, protecting against organ fibrosis and avoiding end-stage organ failure.

\section{EMT in tumorigenesis}

The process of cell de-differentiation via EMT is currently accepted as one of the hallmarks of cancer $(25,26)$. EMT is crucial in the initiation of tumor cell migration and metastasis development. Once the cancer cells begin to metastasize, they must first overcome anoikis. Cancer cells may avoid anoikis via different methods associated with EMT. E-cadherin and cytokeratins are proteins typically found in epithelial cells and their decreased expression is an important feature of EMT. In mesenchymal cells, these proteins are replaced by mesenchymal-specific factors, including fibronectin, vimentin, or neural cadherin (N-cadherin) (12). The changes in the expression of E-cadherin/N-cadherin are positively correlated with the avoidance of anoikis and an increase in cell invasiveness (27). Furthermore, it has been demonstrated that dysregulation of growth factor receptors may result in resistance to anoikis. Before cancer cells begin to migrate, they must activate the genes that are necessary in various processes, such as cell differentiation, proliferation, activation of anti-apoptotic pathways, alteration of cellular characteristics from the epithelial to the mesenchymal phenotype, proteolytic digestion of the receptors that are involved in cell-cell junctions, increased activity of adhesion molecules that assist in cell movement, and the activation of proteases on the cell surface, which digest components of the ECM (10). Due to the heterogeneity of cancer cells, various epigenetic patterns may support these cellular changes (7). In addition, all cells cannot enter the EMT process simultaneously, and only a few at a time may successfully initiate metastasis and progression. Cancer progenitor cell phenotype, intracellular and extracellular signaling, epigenetic modifications, and environmental factors all strongly affect cells entering the EMT process and metastasis. Studies using different types of cancer cell lines or animal tumor models have demonstrated the relevance of
EMT to metastasis. By contrast, EMT during tumorigenesis in humans is difficult to identify, as cancer cells that exhibit the mesenchymal phenotype share a number of similar molecular and morphological characteristics with stromal fibroblasts $(10,28)$.

Regardless, the research and clinical results on solid tumors, including colorectal, ovarian and breast cancer, have verified the increased expression levels of typical EMT transcription factors, such as SNAIL1 and SNAIL2. Furthermore, these results are positively correlated with a worse prognosis in terms of survival or relapse (29-31). The inhibition of EMT may improve the efficiency of traditional curative therapy based on the data from pancreatic, lung and hepatic cancer cells (32-34).

\section{Molecular mechanisms of EMT regulation}

The molecular steps that regulate EMT are highly evolutionarily conserved. The key factors in EMT are transcriptional factors (TF), such as SNAIL, ZEB and TWIST, and their target, E-cadherin. Various signaling pathways involved in the induction and modification of EMT during different steps of embryogenesis or tumorigenesis, including TGF- $\beta$ /bone morphogenetic protein, Wnt/ $\beta$-catenin, tyrosine kinase receptor, T-lymphoma invasion and metastasis inducing protein 1/Rac family small GTPase 1, and Hedgehog signaling, have been identified. These signaling pathways regulate EMT in a context-dependent manner (35).

Inducers and TFs. TGF- $\beta$ is a cytokine that is considered to be a primary inducer of EMT (Fig. 1) (36). It is also considered a facilitator of metastasis with a complex role in cancer development. The TGF- $\beta$ signaling pathway is crucial to the regulation of cell proliferation, differentiation, invasion, migration, apoptosis and modification of the microenvironment, as well as to cancer metastasis (37). TGF- $\beta$ binds to two different serine/threonine kinase receptors, referred to as TGF- $\beta$ receptor type I (T $\beta R I)$ and type II (T $\beta R I I)$, which may activate SMAD and non-SMAD signaling pathways, respectively. Activated T $\beta$ RI phosphorylates the receptor-specific SMAD2/3 elements that are associated with SMAD4. Together, these elements form a heterogenic complex, which is transported into the nucleus and is responsible for the regulation of the transcription of a number of genes, including those involved in EMT activation (38). The ability of the TGF- $\beta$ /SMAD signaling cascade to activate EMT is dependent on the collaboration with other signaling pathways, such as the Ras kinase cascade, through the activation of tyrosine kinase receptors and the cooperation of the Wnt/ $\beta$-catenin/lymphoid enhancer-binding factor-1 signaling pathway (39). The TGF- $\beta$ signaling pathway may regulate, and be regulated by, different signals, as aforementioned. Furthermore, metabolic and mechanical stresses, such as tissue hypoxia, inflammatory cytokines and ECM stiffness, may act as powerful inducers of EMT followed by invasion of cancer cells $(40,41)$. It was demonstrated that one of the main sources of TGF- $\beta$ in carcinomas are the stromal fibroblasts, which were observed in the tumor niche (25). Notably, the TGF- $\beta$ cytokine exerts different effects at various cancer stages. It maintains cell proliferation and differentiation 


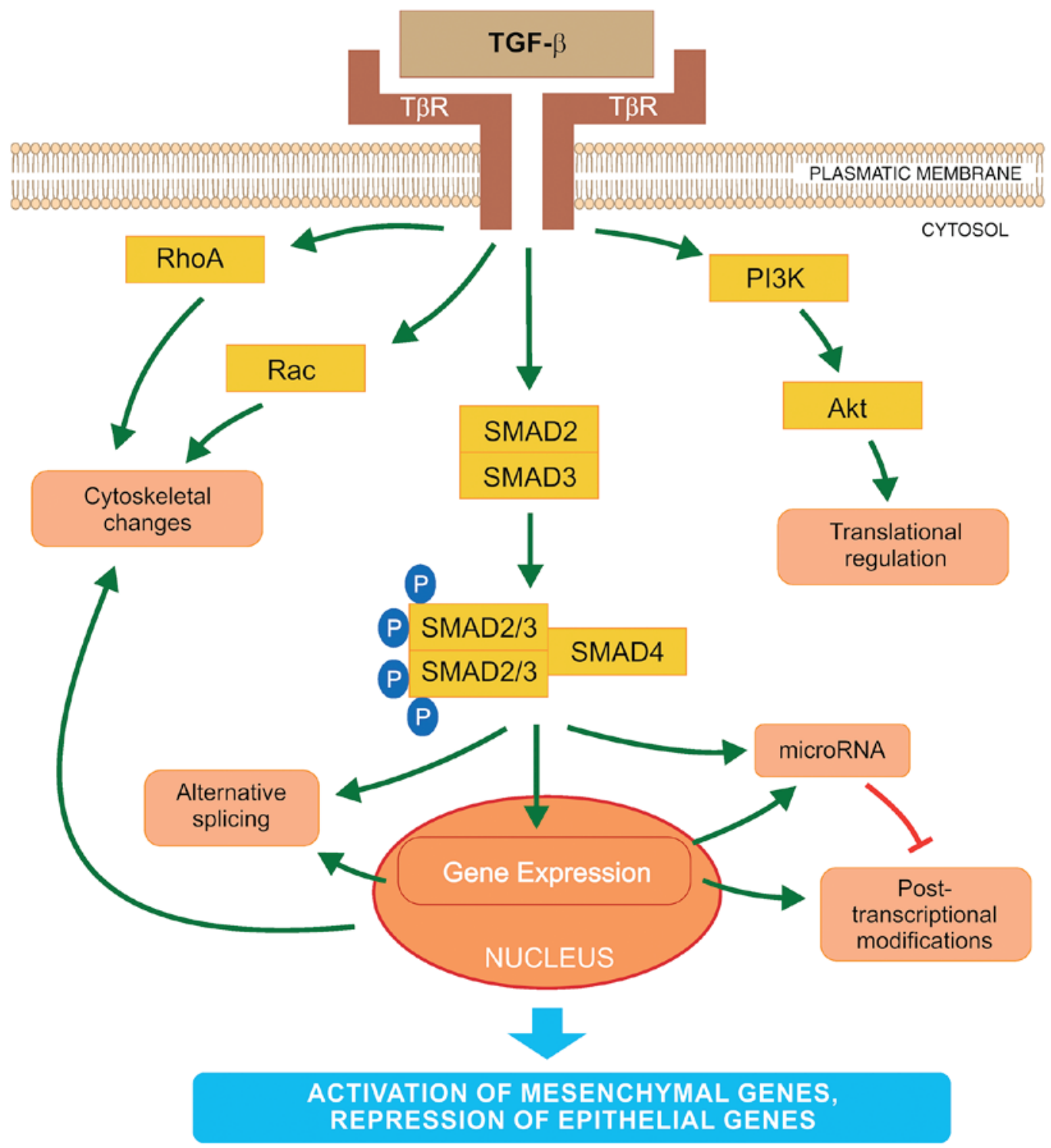

\begin{tabular}{|c|c|}
\hline \multicolumn{2}{|c|}{ SNAIL family } \\
\hline Activation & Repression \\
\hline $\mathrm{N}$-cadherin & E-cadherin \\
\hline Fibronectin & Cytokeratins \\
\hline Vitronectin & Claudins \\
\hline MMPs & Desmoplakin \\
\hline Twist 1/2 & Occludin \\
\hline IDs & Plakophilin \\
\hline ZEB 1/2 & \\
\hline
\end{tabular}
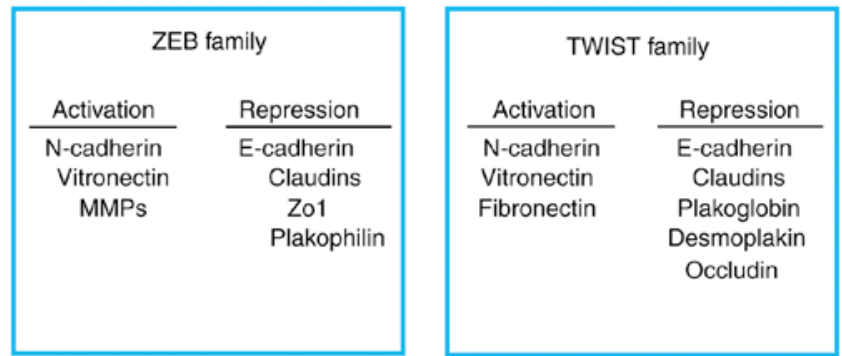

Figure 1. Schematic representation of EMT activation via TGF- $\beta$. The initiation and progression of EMT is regulated at all levels of macromolecule synthesis (transcription/post-transcriptional modifications and translation/post-translational modifications). TGF- $\beta$ binds to its receptors (T $\beta R$ ) and activates EMT via the SMAD signaling pathway. SMAD2/3 are bound to the SMAD4 protein and this phosphorylated complex is translocated into the nucleus where it interacts with transcriptional factors to regulate the expression levels of EMT-specific genes. The key transcriptional factors of EMT are SNAIL, ZEB and TWIST. These are important for the activation or repression of various genes that encode proteins involved in the transition. Furthermore, TGF- $\beta$ activates microRNA expression that regulates gene expression at the post-transcriptional level. By contrast, EMT transcription regulators may decrease the expression levels of specific microRNAs that affect the EMT factors important in the mesenchymal-like phenotype. Furthermore, TGF- $\beta$ may induce EMT via a non-SMAD pathway, by activation of the PI3K-AKT signaling cascade, which may lead to translational regulation of EMT factors. TGF- $\beta$ also initiates a decrease in the number of cell junctions and activates the cytoskeletal reorganization via RHO-GTPases. EMT, epithelial-to-mesenchymal transition; TGF- $\beta$, transforming growth factor- $\beta$; SNAIL, Snail family zinc finger transcriptional factors; TWIST, Twist family BHLH transcriptional factor; ZEB, zinc finger E-box binding homeobox; PI3K, phosphoinositide 3-kinase.

under physiological conditions or in early-stage cancer; however, it also promotes cancer cell invasion and metastasis in late-stage cancer (42).
TGF- $\beta$ directly activates EMT core TFs (SNAIL, ZEB and TWIST), which are the key regulators of this process. The first group of TFs is the SNAIL zinc finger family, consisting 
of SNAIL1 and SNAIL2 (also referred to as SLUG). The two are able to bind to the E-box sequences in the promoter region of the E-cadherin gene leading to its transcriptional repression. The elevated expression of SNAIL1 in breast cancer cell lines resulted in the loss of cell-cell junctions due to a decrease in E-cadherin production, followed by significant changes from the epithelial to the mesenchymal spindle cell phenotype, with an accompanying increase in cell mobility and invasiveness (43). Although TGF- $\beta$ is crucial in the activation of SNAIL1 expression, other factors, such as Wnt family proteins, neurogenic locus notch homolog protein (Notch) and certain growth factors (via tyrosine kinase receptors) also activate the expression of SNAIL1, depending on the physiological or pathological conditions (44). SNAIL1 and SNAIL2 work synergistically with other TFs and regulate the expression of various genes involved in EMT. By contrast, TGF- $\beta$ may activate the apoptotic pathway, thus, tumor cells must avoid this type of cell death. SNAIL1 increases the expression levels of B-cell lymphoma-extra large $(\mathrm{Bcl}-\mathrm{xL})$ and $A k t$, which leads to the inhibition of apoptosis mediated by TGF- $\beta$ (45). Furthermore, SNAIL downregulates the expression of cyclin $D 2$, which negatively affects the cell cycle. When tumor cells begin to differentiate, their proliferation is reduced. In the tumor niche, expression of SNAIL may be activated via numerous factors, including: i) The cytokine tumor necrosis factor (TNF)- $\alpha$ via nuclear factor (NF)- $\mathrm{kB}$ activation in response to inflammation and ii) hypoxia-inducible factor (HIF)-1, HIF-2 and Notch in response to hypoxia (46).

The second group of TFs is the zinc finger E-box-binding family proteins, ZEB1 and ZEB2, which also downregulate $E$-cadherin expression. ZEB expression is downregulated as follows: i) Post-transcriptionally via miR-200 (a double-negative feedback loop) and ii) post-translationally by SUMOylation of ZEB2, which prevents its nuclear translocation and attenuates ZEB2-mediated gene expression $(47,48)$. ZEB expression is often followed by activation of SNAILs and direct targeting of the expression of the $Z E B 1$ gene by SNAIL1. The activity of ZEB is regulated by certain signaling pathways, such as TGF- $\beta$ and Wnt, as well as by the Ras-MAPK signaling cascade (49). It was also demonstrated that members of the ZEB and SNAIL families may decrease the expression of factors involved in tight junctions, including connexins junctional adhesion molecule 1/A, or zonula occludens-1 (50).

The third group is a typical helix-loop-helix family of TFs, including TWIST1, TWIST2, inhibitor of differentiation proteins (ID) and E12/E47. These factors induce EMT alone or by acting synergistically (51). Therefore, similar to SNAIL and ZEB, TWIST binds to the E-boxes of the promoter region of the E-cadherin gene and acts as transcriptional repressor or activator, leading to the repression of genes involved in the epithelial phenotype and to the activation of EMT genes. In tumor cells, TWIST1 decreases E-cadherin and increases $N$-cadherin expression levels independent of SNAIL activity (52). TNF- $\alpha$ induces the expression of TWIST1 via the NF- $\mathrm{BB}$ signaling pathway (53). In the tumor niche, other cytokines may activate Stat 3 via Janus kinase and lead to the induction of TWIST1 activity (54). In addition, the regulation of interaction between TWIST1 and HIF-1 $\alpha$ was analyzed. Hypoxia or overexpression of HIF-1 $\alpha$ leads to the activation of EMT and metastatic phenotypes. HIF-1 may regulate the expression level of TWIST by binding directly to the hypoxia-response element in the proximal promoter region of TWIST (55). Furthermore, TWIST1 activates invadopodia-mediated matrix degradation, followed by degradation of the basement membrane during EMT (41).

Recently, other TFs contributing to and controlling the EMT/MET cell plasticity were identified, including members of the activator protein-1 (Jun/Fos) family, forkhead box protein C2, Kruppel-like factor 4, paired related homeobox 1, p53, SRY-box (Sox)4, Sox9 and TEA domain transcription factor 2 (56). Based on their specificity, the same EMT TFs may serve as molecular markers of EMT during cancer progression.

Effectors. Activation of EMT TFs lead to reduction in the transcription of specific genes encoding proteins involved in adherens and tight junctions, desmosomes, and maintaining the apical-basal cell polarity (6). These junctions support the epithelial phenotype and control various signaling pathways through their associated proteins. Therefore, dysregulation of cell-cell junctions significantly affects a number of molecular pathways that further activate EMT and cancer invasion. For example, $\beta$-catenin released from the complex with E-cadherin crosses into the nucleus and promotes the transcription of Wnt-target genes to initiate EMT. Furthermore, the transcription of genes involved in the mesenchymal phenotype, such as fibronectin, vimentin or $\mathrm{N}$-cadherin, is increased (57). Various non-epithelial cadherins (N-cadherin), cell surface proteins (CD44) and integrin $\beta 6$, are induced and may be crucial for the migration of cancer cells (58). In epithelial cells, the cytoskeletal network connected to desmosomes is destroyed. Expression of vimentin is upregulated, which results in the actin and intermediated filament reorganization (59). The transformation into the mesenchymal phenotype promotes cell migration and the formation of actin-rich membrane protrusions (invadopodia). In addition, actin fibers increase cell contractility. The formation of invadopodia and increased activity of MMPs results in the degradation of adherens junctions and other cell surface proteins, as well as ECM fibers, which increases cancer cell motility and promotes breaking through the basement membrane and the invasion of neighboring tissues (26).

E-cadherin is considered a gatekeeper of the epithelial phenotype. It is one of the main targets for MMP digestion and its degradation allows tissue reorganization into single cells and the activation of other signals important in EMT induction. Cleavage of the E-cadherin ectodomain creates soluble E-cadherin fragments that are important in EMT induction, invasion and proliferation via estimated Glomerular Filtration Rate signaling (60).

It is known that certain epithelial markers, such as epithelial cell adhesion molecule (EpCAM) and cytokeratins, are downregulated during EMT (61). EpCAM, a transmembrane protein, is important for intercellular connections in the epithelium. It has oncogenic potential, as it upregulates the activity of cyclin A, cyclin E and c-Myc (62). Cytokeratins are proteins of the keratin-containing intermediate filaments. EpCAM and cytokeratins may be used as biomarkers for CTC detection in the blood of patients with cancer (63).

Epigenetics. Embryogenesis is a process of cell differentiation and growth, controlled predominantly via epigenetic events. 
Similarly, epigenetic modification was found to be a key event in cancer cells and cancer progenitor cells that undergo EMT followed by metastasis initiation (10). The development of cancer has long been characterized based upon genetic regulation, although it has been demonstrated that epigenetic modifications perform a critical role $(7,10)$. Epigenetics is the study of the variations and changes in the expression levels of genes that are independent from alterations in the DNA sequence. These changes include methylation of DNA and histones, acetylation and phosphorylation, or their reverse processes, as well as variations in microRNA expression. Hypermethylation of $\mathrm{CpG}$ islands in the DNA sequence leads to gene silencing and affects transcription (64). Epigenetic changes are variable and grade-specific. They occur in different cell processes and at different time-points, for example cell growth is decreased and cell differentiation is activated. When cancer cell differentiation is accomplished, cell growth is activated and novel mutations appear. The reverse reactions occur during MET. Epigenetic modifications that support the EMT/MET process are variable and dynamic; their role in metastasis development and cancer progression has been extensively investigated $(7,10)$.

T $\beta$ Rs are highly active during EMT. It has been hypothesized that the differentiation of cancer cells is not required at the terminal level of metastasis and, thus, $T \beta R$ transcription is silenced by methylation (10). Inhibition of HDAC activity leads to the suppression of EMT, which is mediated by the epigenetic modification of T $\beta R I$ in human renal epithelial cells (65).

The epigenetic changes are present in cancer cells, as well as in stromal cells. However, this finding does not clarify whether the differentiation of metastatic cells occurs simultaneously or at different and specific time-points. Epigenetic drifts have recently attracted attention in cancer research; these include age-dependent alterations in DNA methylation patterns. Epigenetic drifts may be tissue-specific. Furthermore, these drifts may affect the differentiation of stem cells and lead to a decrease of their stemness during aging. Furthermore, the expression of certain microRNAs is controlled by methylation (66). The expression of another family of regulatory RNAs, long non-coding RNAs (lncRNAs), may also be controlled by epigenetics. For example, IncRNA H19 suppresses E-cadherin expression in bladder cancer via hypomethylation, resulting in enhanced metastatic progression (67).

Epigenetic changes may affect cell differentiation and proliferation. In various cancer types, cell cycle regulator proteins, such as p16, p21, p27 and p53, have been controlled by methylation silencing (68). A DNA repair enzyme, O6-methylguanine DNA methyltransferase (MGMT), is another example of epigenetic silencing. It was demonstrated that augmented methylation of the promoter region of the $M G M T$ gene in cancer cells increases the sensitivity of DNA to damage by alkylating agents, such as temozolomide (69).

DNA methylation is generally catalyzed by DNA methyltransferases (DNMT). DNMT3a, as well as DNMT3b, regulate de novo methylation of DNA in the developing embryo, and DNMT1 is responsible for DNA methylation between cell divisions. Additionally, DNMT1 is significantly overexpressed in tumor cells (70). Two groups of proteins, histone deacetylases (HDAC) and methyl-binding domain proteins, are important in downregulation of methylation of the promoter region of the $\mathrm{CpG}$ islands. These proteins bind close to the promoter region, thus inhibiting the binding of RNA polymerase II, followed by inhibition of transcription. The levels of HDACs 1,2 and 6 are highly elevated in cancer cells (71). Furthermore, during the increased acetylation of histones, HDAC inhibitors demethylate $\mathrm{CpG}$ residues by decreasing DNMT1 activity (72). The changes to histone modifications are important in gene silencing in cancer cells. The expression of tumor suppressor genes may be regulated by epigenetic silencing, which subsequently leads to inhibition of the apoptotic pathway and to cancer development. Apoptosis is a precisely controlled pathway of cell death that occurs during growth, and regulates the cell population in adult organisms. The dysregulation of apoptosis is a typical feature of cancer cells (73).

Alternative splicing. Alternative splicing may enable the encoding of various protein isoforms, with possible antagonistic functions, by one gene. It was recently demonstrated that this post-transcriptional modification may exert an important effect on EMT regulation (74).

The invasion isoform of the Mena $\left(\mathrm{Mena}^{\mathrm{INV}}\right)$ protein is produced in aggressive cancer cells. Mena ${ }^{\mathrm{INV}}$ promotes invasiveness via the stabilization of invadopodia maturation (75). Two RNA-binding proteins, termed epithelial splicing regulatory proteins (ESRP)1 and ESRP2, regulate the splicing of EMT-associated genes, such as fibroblast growth factor receptor 2, Mena, p120-catenin and erythrocyte membrane protein band 4.1 like 5. In a study of pancreatic adenocarcinoma, metastatic cancer cells displayed specific splice variants of CD44 that were not present in the primary cancer cells. ESRP1 acts as an inhibitor of the CD44 isoform, which is important during EMT. Furthermore, SNAIL inhibits ESRP1, leading to elevated expression levels of the CD44 isoform, which is associated with the de-differentiation and increased invasion of cancer cells (76). Alternative splicing of various genes encoding proteins responsible for invasion was observed in breast cancer cells undergoing EMT (74).

MicroRNAs. MicroRNAs are a group of non-coding, highly conserved, single-stranded 19-25 nucleotide-long RNA molecules. MicroRNAs control gene expression post-transcriptionally via interaction with the $3^{\prime}$ untranslated region (UTR) of mRNA, resulting in its degradation or inhibition of translation. Despite the 3'UTR specificity, microRNAs interact with a number of different mRNAs (7). MicroRNAs are able to regulate transcription in development, as well as in tumor cells, and they have been associated with germline, muscle and neuronal development (77). The regulatory role of microRNAs and EMT key inducers in cancer cells was recently demonstrated (66). However, despite the fact that the associations between the expression levels of certain microRNAs in specific tumors have been extensively investigated, little is known regarding the mechanisms underlying these associations. It is important to identify specific microRNA targets and determine how microRNAs initiate metastasis development and progression.

Numerous studies have analyzed the association between the miR-200 family of microRNAs and ZEB regulators (78). 
miR-200 interacts with the 3'UTR region of ZEB mRNA, followed by the downregulation of ZEB expression and increased epithelial differentiation. Furthermore, ZEB1/ZEB2 TFs may interact, via their ZEB binding sites, with the promoter region of the miR-200 family and reverse control miR-200 transcription. This feedback regulation of ZEB1/ZEB2 and miR-200 family members controls cell morphology, as well as cell migration and invasion (79). Different double-negative feedback loops between microRNAs and key EMT TFs have been identified, and they are important underlying mechanisms of EMT regulation, reversibility and cell plasticity (80). Apart from its regulatory role in EMT, the ZEB/miR-200 feedback loop is important in stem-like phenotypes (81). The Notch pathway has been identified downstream of ZEB/miR-200 signaling. The Notch cascade regulates various processes in cells, such as EMT or stemness. Dysregulation of the Notch pathway has been observed in various types of cancer. Members of the miR-200 family affect the mRNA of Notch pathway factors, including Jagged1 and Mastermind-like co-activators (Maml2 and Maml3). Furthermore, Notch stimulates ZEB1 expression and promotes the mesenchymal stem-like cancer cell phenotype (82).

It has been demonstrated that aberrant expression of p53 may increase the activity of certain microRNAs, including members of the miR-192 and miR-200 families, leading to the downregulation of factors, such as B lymphoma Moloney murine leukemia virus insertion region 1 and $\mathrm{ZEB}$, which are involved in EMT and cell stemness $(81,83)$. Other members of the miR-200 family (miR-10b, miR-373 and miR-520c) have been associated with the progression of breast cancer. In addition, the expression level of miR-21 was found to be highly overregulated in EMT mediated by the TGF- $\beta$ signaling pathway (66).

MicroRNAs regulate the expression of E-cadherin directly or indirectly. This transmembrane glycoprotein is a crucial factor of the adherens junctions in the epithelium, and is involved in structural and intracellular signaling. E-cadherin is post-transcriptionally downregulated by miR-9. It was demonstrated that miR-9 is highly overexpressed in the primary breast tumors of patients with metastases, compared with non-metastatic patients. An aberrant expression of miR-9 activates EMT, and results in $\sim 70 \%$ reduction in E-cadherin expression and the activation of vimentin expression (84).

In conclusion, numerous EMT TFs, microRNAs, epigenetic modifications, lncRNAs and alternative splicing factors appear to control the process of EMT at various molecular levels. However, the epistatic hierarchy of these regulatory networks must be established.

\section{Different types of metastatic cancer cells}

CTCs (Fig. 2) have attracted increasing attention due to their crucial function in metastasis development. CTCs were first detected by a pathologist, Thomas Ashworth, in the blood of a male patient with metastatic disease $>150$ years ago (85). However, for more than a century, research focused on CTCs was not possible due to technological limitations. Recently, CTC characterization has become more widespread with the technological advances in detection and separation methods.
Another milestone in cancer research was the identification of CTC clusters (Fig. 2). CTC clusters represent a class of $>2$ to $<100$ cancer cells with efficient cell-cell interactions found in the circulation. In 1954, Watanabe demonstrated the function of CTC clusters in metastasis formation by proving that cancer cells in clusters were able to form metastases, while individual cells were not (86). Research over the last 20 years has verified this observation, using various cancer cell types and colon cancer-derived liver metastasis or melanoma-derived lung metastasis. It was demonstrated that metastasis development is dependent on the quantity, as well as on the size, of the CTC clusters (9).

Another group of tumor cells, referred to as dormant tumor cells (DTCs), was identified to be important in metastatic progression (Fig. 2). These cells may remain dormant for numerous years prior to re-growth. However, due to insufficient specific markers for the detection and isolation of DTCs in the epithelium of cancer patients or animal models, current knowledge of this process is solely derived from bone marrow micrometastasis. Watson et al (87) isolated and analyzed the molecular profile of micrometastases from the bone marrow, and identified TWIST1 as a factor in the detection of early tumor relapse in breast cancer patients. However, further studies focusing on EMT during cancer dormancy are required.

CTCs and CTC clusters in the circulation. CTCs do not migrate through the bloodstream alone, and also receive support from other non-tumor cells. Platelets rapidly coat CTCs, protecting them from violent shear forces. Tumor cells interact with the platelet's adhesive proteins (fibronectin and von Willebrand factor) through integrins, supporting cluster formation (88). Coagulates of tumor cells and platelets create microemboli, which become entrapped in small vessels and, thus, require a longer time to enter tissues. Furthermore, platelets support adhesion to the luminal side of the endothelium. Notably, platelets also form a shield against immune cells via the inactivation of natural killer (NK) group 2D receptors on NK cells and T lymphocytes (89). Immune attenuation arises via the transfer of major histocompatibility complex I complexes from granulated platelets to CTCs, obtaining a new 'self' identity and preventing NK cell-mediated cytolytic attacks. However, CTCs survive only for 1-2.4 h in the circulation based on in vivo experiments; the majority of CTCs die in the circulation due to shear stresses and/or anoikis (90).

Recently, CTC clusters were identified to possess different properties compared with single CTCs, including for phenotype, gene expression profile and dissemination activity. Our current knowledge indicates that metastasis arising from CTC clusters is equally important to that arising from CTCs. Apart from tumor cells, CTC clusters contain non-tumor cells, such as mesenchymal, epithelial and immune cells, platelets, pericytes or fibroblasts (91). These non-tumor elements help CTC clusters to survive and effectively metastasize. For example, tumor-associated stromal cells (endothelial fibroblasts and tumor-infiltrated myeloid cells) promote the survival of cancer cells in CTC clusters, and promote the growth of metastases (Strnádel; unpublished data). Furthermore, following a reduction in the number of tumor-derived fibroblasts in CTC clusters, decreased 


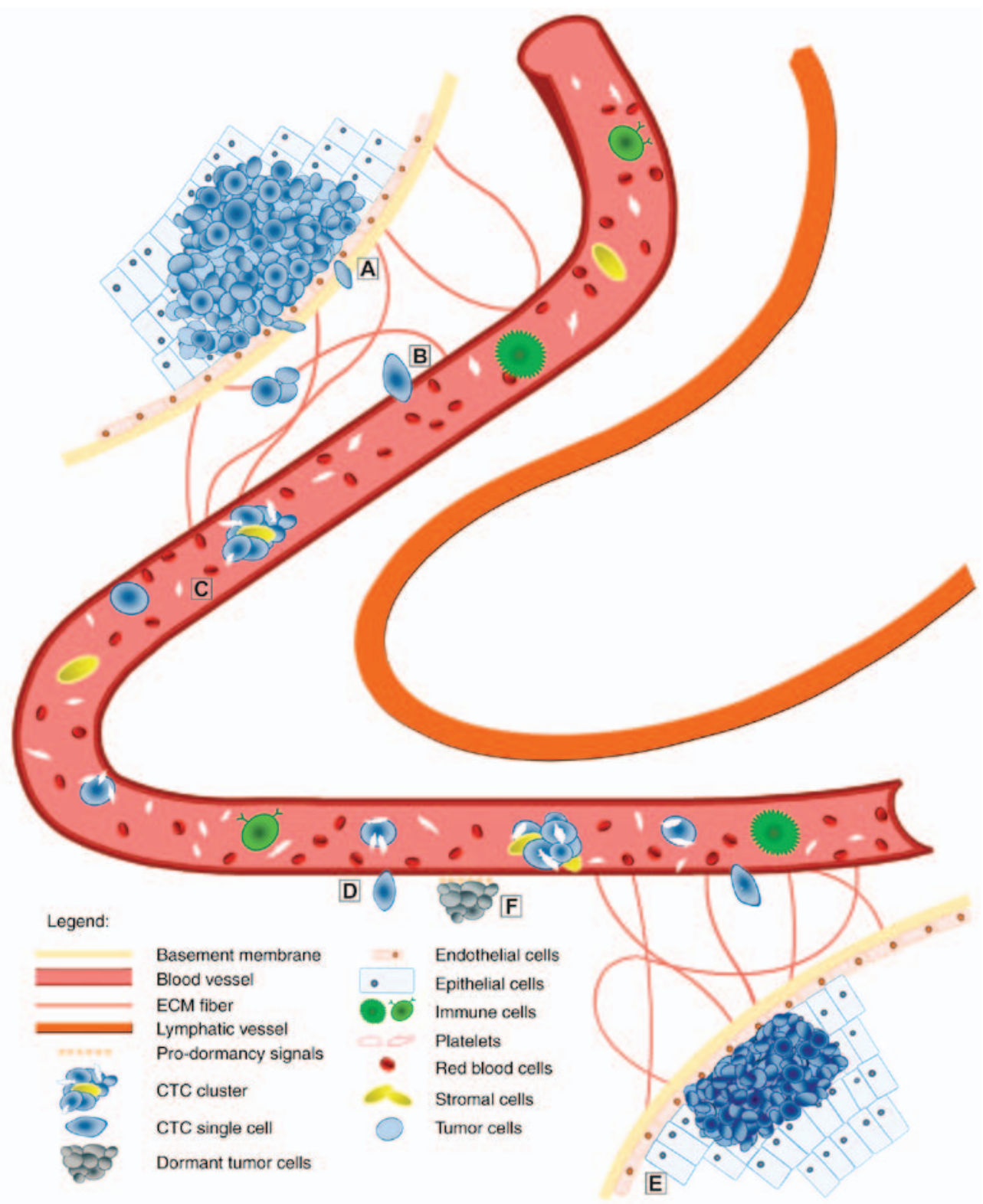

Figure 2. Overview of the EMT/MET process in tumor metastasis. The epithelial cells undergo a genetic transformation to become cancer cells. Genetic factors and the cancer cell microenvironment initiate the malignant conversion via the EMT process. Detached tumor cells may penetrate through the basement membrane and degrade extracellular matrix (A). Subsequently, they intravasate (B) the circulation (blood or lymphatic vessels). When CTCs or CTC clusters are in the circulation (C), only a small number survive various attacks. The surviving cells undergo transition, which is necessary during extravasation into the tissues (D). This seeding of migrating cancer cells may occur quickly. In the novel stromal environment, tumor cells form micrometastases with the ability to generate fully malignant secondary tumors (E). However, extravasated tumor cells may remain dormant (F) over a long time period before they activate the MET process and proliferate to form macrometastases. EMT, epithelial-to-mesenchymal transition; MET, mesenchymal-to-epithelial transition; CTCs, circulating tumor cells.

metastatic activity was observed. When mouse mammary tumor cells were co-cultured with endothelial cells in 3D spheroids, promotion of angiogenesis was observed in cancer cells, resulting in greater numbers and larger sizes of metastatic lesions (92). Platelets in the CTC clusters, as in CTCs, may protect cancer cells from immune attacks and blood shear damage by physical shielding and 'platelet mimicry'. In addition, laboratory evidence indicates that activated platelets interact with cancer cells within the tumor microenvironment via paracrine signaling and direct contact (93). Other unspecified cells, including cytokeratin-positive dendritic cell-like cells have been detected in CTC clusters, although their biological function remains unknown (9).
Metastatic activity of CTCs and CTC clusters. Research into the biological properties of CTCs may improve our understanding of their metastatic activity in humans. The presence of CTCs in colorectal, breast, pancreatic, lung and prostate cancer support their role in cancer cell dissemination and invasion during metastasis development, which is associated with a poor clinical outcome (94-98). The co-expression of the two sets of genes, namely mesenchymal and epithelial, was confirmed in CTCs from various cancer types, while not in the corresponding primary tumor cells. Furthermore, high numbers of CTCs with increased expression levels of EMT factors (e.g., SNAIL, TWIST or vimentin) were detected in patients with advanced-stage cancer, compared with in those 
with early-stage cancer. This may indicate that CTCs should prevail during cancer progression and contribute to metastatic outgrowth (26). Mego et al (99) analyzed the expression levels of the EMT regulators, TWIST and SNAIL in CTCs from breast cancer patients, and demonstrated a positive correlation between the increased expression levels of these factors and the prediction of early disease relapse. In hepatocellular carcinoma patients, the overexpression of vimentin and TWIST in CTCs was positively correlated with cancer progression and increased metastasis development (100). Furthermore, CTCs with a mesenchymal-like phenotype were associated with decreased therapeutic efficacy in lung, colorectal and breast cancer patients.

Various recent studies have focused on the reasons why CTC clusters exhibit a higher metastatic potential when compared with CTCs $(101,102)$. It was demonstrated that interactions between cancer cell-associated mucin 1 and circulating galectin-3 assist by prolonging CTC cluster survival and preventing anoikis, as well as by increasing adhesions between tumor and endothelial cells in CTC clusters (103). These findings may improve our knowledge of the molecular signaling pathways involved in the dissemination of CTC clusters, which may be useful in designing novel therapeutic approaches for the treatment of metastases.

Using an animal model of breast cancer, Aceto et al (8) demonstrated that the metastatic potential of CTC clusters is higher (23-50-fold) compared with single CTCs. Two years later, Cheung et al (104) validated this observation and reported that $\sim 97 \%$ of metastases originate from CTC clusters. However, there remains the question of the origin of CTC clusters: Whether they are actively separated from the primary tumor as a group of cells and migrate into the bloodstream, or whether they are released as single tumor cells and form aggregates once in the bloodstream. Using differentially labeled cancer cells, which were injected into the mammary fat pad of mice, it was demonstrated that CTC clusters could not be formed in the bloodstream, but that they arise from polyclonal primary tumors $(8,104)$. Notably, these CTC clusters form polyclonal metastases at distant sites. Furthermore, Au et al (105) observed that CTC clusters with $<20$ cells reorganize into single chain-like formations, which helps to decrease hydrodynamic resistance and simplifies their passage through small vessels. The plasticity of CTC clusters is particularly high, and chain-like cells are reorganized to spheroid-shaped clusters after passing through the small blood vessels. These results improved our understanding of CTC cluster flexibility during invasion. The EMT phenotype in CTCs is not particularly stable, and may change as part of the response to therapy. It was demonstrated that CTC clusters may express more mesenchymal factors in patients during anticancer therapy. The CTC cluster phenotype is a mixture of epithelial and mesenchymal characteristics, to which the high plasticity of this complex is attributed (8). Recently, Cima et al (106) demonstrated the presence of non-cancer tumor-derived circulating endothelial cell clusters in colorectal cancer. Clusters of endothelial cells expressed mesenchymal, as well as epithelial factors, although they did not display the genetic variations of the primary tumor. The presence of benign endothelial clusters may provide novel insights into tumor vasculature during therapy (107).

\section{Methods for CTC and CTC cluster detection}

Although aggressive tumors release thousands of CTCs into the blood stream daily, CTCs and CTC clusters are rarely identified in the circulation. In the peripheral blood, a count of one single CTC per $10^{5}-10^{7}$ mononuclear cells may be expected, while CTC clusters are even more rare. These cells represent only $3 \%$ of detected circulating cells (8). For the detection of these cells in the blood, methods allowing the enrichment of their fraction prior to detection are required. In recent years, significant efforts have been made to develop appropriate methods for the enrichment and identification of CTCs. Methods for CTC and CTC cluster detection, and isolation must be highly specific to distinguish CTCs from blood elements. A number of techniques, which are focused on CTC enrichment, have used specific markers to separate CTCs from leukocytes. Cytokeratins and EpCAM are predominantly applied as common epithelial markers $(63,107)$.

By contrast, previous studies using cell lines or patient samples demonstrated that $20 \%$ of cells exhibited decreased EpCAM expression levels. In these cells, the increased expression levels of mesenchymal markers and the decreased expression levels of epithelial markers have been verified. It was hypothesized that the detection of mesenchymal-like cells may hinder or underestimate the number of CTCs based upon the expression level of EpCAM (108). This observation may be significant for prognosis, as EpCAM-CTCs from the blood samples of breast cancer patients may produce a specific population of CTCs (positive for human epidermal growth factor receptor 2/epidermal growth factor receptor/heparanase/Notch1), which metastasize to brain tissue (109). Furthermore, the selection of CTCs based on the presence of EpCAM may falsely identify normal cells as cancer cells. It was demonstrated that even erythroid progenitor cells from the bone marrow may temporarily express EpCAM. However, prostate cancer cells disseminated in the bone marrow, which show dormancy signatures, also exhibited EpCAM positivity (110).

CTC clusters display a combination of epithelial and mesenchymal features. Therefore, the detection methods that are based upon the presence of typical epithelial markers may underestimate the number of CTC clusters (111). Techniques for CTC isolation and detection use their specific characteristics to distinguish them from blood cells, including: i) Physical properties, such as cell density, size and electrical charge; and ii) biological properties, including the expression of specific surface markers and invasion potential. Therefore, a number of techniques are based on the immunoaffinity properties, using specific antibodies bound to magnetic beads to enrich the CTC fraction and avoid leukocyte contamination (112). Only one method, the CellSearch system, is currently validated by the USA Food and Drug Administration for clinical use (113). A good prognostic outcome for cancer patients is considered to be the detection of $<5$ circulating cells per $7.5-\mathrm{ml}$ blood sample. CellSearch was used for CTC detection in various types of cancer, including colorectal, prostate and breast cancer. The benefit of this technique is its reproducibility, while its disadvantage is a lower level of CTC detection due to their epithelial-mesenchymal plasticity. Other detection methods, 
such as Parsortix and ScreenCell, are based upon the physical properties, with size-based enrichment platforms. These methods take advantage of the slightly bigger size of CTCs compared with white (WBCs) and red blood cells (RBCs; WBCs are sized approximately 7-15 $\mu \mathrm{m}$; RBCs are $\sim 8 \mu \mathrm{m}$; and single CTCs are approximately $12-25 \mu \mathrm{m})(114)$. Another detection method for CTCs and CTC clusters was recently employed, using a combination of hydrodynamic cell separation and immunomagnetic depletion of antibody-tagged WBCs to isolate larger CTCs. These are recently developed microfluidic devices, such as the spiral biochip or the CTC-iChip (115). Furthermore, based on the rare presence of CTCs, GILUPI Nanomedizin developed a novel method for in vivo CTC enrichment using EpCAM-coated wire that may be inserted into the antecubital vein (116).

\section{Future perspectives}

EMT is a highly complex, dynamic and precisely regulated developmental process that is important during embryogenesis. It is also crucial during metastasis development and the progression of chronic diseases. Thus, EMT/MET are reverse processes, and they represent a complex, highly controlled reversible reaction at different stages during cellular transition. Epithelial cells usually enter EMT simultaneously and express epithelial and mesenchymal markers. It is necessary to investigate the dynamic plasticity and heterogeneity of cancer cells that undergo EMT. Over the past two decades, an intense EMT study has been focused on the EMT/MET process that occurs during in vivo metastasis development, as well as in circulating cells exhibiting the EMT phenotype (117-119). Research data derived from various studied models, including cancer cell lines, animal cancer and human cancer samples, have demonstrated the importance of EMT for successful metastasis development. Due to the lack of detection of the typical EMT markers in CTCs, it is possible that certain tumor cells disseminate and metastasize using a mechanism other than EMT (26). Due to the inability for CTC or CTC cluster detection, the presence of EMT during dissemination cannot be excluded. This may also be due to the limitations of the detection methods. However, there may be different mechanisms underlying invasiveness and metastasis development, and further research is required to identify novel and effective EMT markers for the assessment of the EMT process in tumorigenesis.

One of the accepted theories for cancer relapse is based on the presence of cancer progenitor cells in the tumor, or also in the CTC clusters, as well as the presence of progenitor CTCs in the circulation $(7,10,94)$. The occurrence of progenitor cells in patients who are in remission should alert physicians to the risk of potential cancer relapse. Various clinical studies demonstrated that the combination of standard chemotherapy and epigenetic drugs may be a powerful treatment model for reducing relapse in various cancer types (120). The improvement in cancer treatment may also focus on the increased efficiency of therapy against cancer progenitor cells. However, further research and clinical studies are required to achieve in-depth understanding of the mechanisms underlying epigenetic-based therapies. The hypermethylation of numerous genes is likely to be associated with cancer (121). It has been revealed that the combination of inhibitors, DNMT and HDAC, may represent a promising approach to the treatment of myelodysplastic syndrome (122). This provides the potential to investigate the effect of hypermethylated DNA regions associated with higher DNMT1 activity, which may affect epigenetic modifications of enhancers and TFs, as well as gene expression during carcinogenesis. Modification of histones by acetylation or deacetylation is crucial in epigenetics and chromatin remodeling. Therefore, inhibition of the HDAC activity exerts a strong effect on cancer progression and pathogenesis. The activity of HDAC is markedly increased in various types of carcinoma $(123,124)$. Therefore, HDAC inhibition may negatively affect tumor progression and support the apoptotic process in cancer cells, while healthy tissues would not be affected. HDAC inhibitors have an impact on DNA-histone structure, as well as on the acetylation level of non-histone proteins. Studies analyzing the effect of HDAC inhibitors on cancer progression demonstrated their strong anti-tumor activity. For example, suberoylanilide hydroxamic $\mathrm{acid} /$ vorinostat and romidepsin are used in peripheral and cutaneous T-cell lymphoma therapy (125-127). In addition, panobinostat has been clinically successful in the treatment of multiple myeloma (128). In addition, it has been demonstrated that the HDAC inhibitors applied in breast cancer studies display a strong activity in combination with aromatase inhibitors, cytotoxic drugs, pro-drugs and radiation therapy (120). A number of inhibitors are currently in the advanced stages of clinical testing.

MicroRNAs are also implicated in carcinogenesis and disease progression. Their role in the transition process is obvious and further elucidates EMT regulation. The identification of microRNA downstream and upstream EMT targets may present novel possibilities for biomarker determination during cancer progression, leading to improvements in prognosis and therapy.

There are several questions regarding the biology of CTCs and CTC clusters, including: i) Establishing a standardized method for isolating CTCs or CTC clusters with conservation of their molecular and morphological status; ii) understanding the biological pathways underlying CTC cluster composition and acquiring knowledge on cancer cells that are transformed into CTCs; and, iii) investigating the molecular mechanisms underlying CTC cluster formation, their migration into the circulation and metastasis development at distant sites. Answering these questions may reveal novel areas in CTC and CTC cluster research, and should be considered in future diagnostic and therapeutic approaches.

A deeper understanding of the biology and molecular mechanisms of DTC activation may help to identify specific factors responsible for metastatic progression (129). Future analysis of the dormant niche using mass spectrometry and metabolomics may help to identify proteins and metabolites that lead to the induction and activation of cancer cell dormancy. Development of tissue-specific models that may simulate the native DTC niche is crucial for understanding the dynamic changes that occur in the tumor niche following chemotherapy treatment. Novel markers or molecular pathways involved in tumor cell dormancy initiation and progression are required for further studies (90). Therefore, the optimal therapy may be a specific treatment that is applied directly following detection 
of the primary tumor, in order to avoid the dissemination and dormancy of cancer cells.

Research and clinical studies support the significance of EMT in tumorigenesis. Therefore, novel treatments focused on CTC clusters and DTC elimination, in combination with conventional therapies, should decrease metastasis, progression and resistance to specific drugs. For example, certain preclinical studies have focused on testing the effect of low-molecular-weight compounds on EMT-inducing factors and their signaling cascades (130). Based on the present knowledge of cellular and molecular variability during EMT, therapeutic interventions based on anti-EMT treatment may be precisely planned and applied. Therefore, preventing the transition process may be useful during treatment of primary tumor cells that are able to change their epithelial phenotype to a mesenchymal phenotype. Additionally, the novel markers, including transcriptome analysis of EMT characteristics from primary tumors and from CTCs or CTC clusters, may facilitate with understanding the response to treatment and with improving patient prognosis, as well as in designing novel cancer treatments.

\section{Acknowledgements}

The authors would like to thank Mrs. Zuzana Necpalová (TJTN Matúš, Slovakia) and Mr. Miroslav Škoviera (Lutheran Academy in Martin, Slovakia) for figure preparation. The current study was supported by the following grants: Slovak Scientific Grant Agency (grant no. VEGA 1/0178/17), Research and Development Support Agency (grant no. APVV-15-0217) and the project 'Biomedical Center Martin', (ITMS code 26220220187) co-financed from EU sources.

\section{References}

1. Nakaya Y and Sheng G: Epithelial to mesenchymal transition during gastrulation: An embryological view. Dev Growth Differ 50: 755-766, 2008.

2. Qin Q, Xu Y, He T, Qin C and Xu J: Normal and disease-related biological functions of Twist1 and underlying molecular mechanisms. Cell Res 22: 90-106, 2012.

3. Piera-Velazquez S, Li Z and Jimenez SA: Role of endothelialmesenchymal transition (EndoMT) in the pathogenesis of fibrotic disorders. Am J Pathol 179: 1074-1080, 2011.

4. Fidler IJ: The pathogenesis of cancer metastasis: The 'seed and soil' hypothesis revisited. Nat Rev Cancer 3: 453-458, 2003.

5. Książkiewicz M, Markiewicz A and Zaczek AJ: Epithelial-mesenchymal transition: A hallmark in metastasis formation linking circulating tumor cells and cancer stem cells. Pathobiology 79: 195-208, 2012.

6. Nieto M: Epithelial plasticity: A common theme in embryonic and cancer cells. Science 342: 1234850, 2013.

7. Sarkar S, Horn G, Moulton K, Oza A, Byler S, Kokolus S and Longacre M: Cancer development, progression, and therapy: An epigenetic overview. Int J Mol Sci 14: 21087-21113, 2013.

8. Aceto N, Bardia A, Miyamoto DT, Donaldson MC, Wittner BS, Spencer JA, Yu M, Pely A, Engstrom A, Zhu H, et al: Circulating tumor cell clusters are oligoclonal precursors of breast cancer metastasis. Cell 158: 1110-1122, 2014.

9. Hong Y, Fang F and Zhang Q: Circulating tumor cell clusters: What we know and what we expect (Review). Int J Oncol 49: 2206-2216, 2016.

10. Heerboth S, Housman G, Leary M, Longacre M, Byler S, Lapinska K, Willbanks A and Sarkar S: EMT and tumor metastasis. Clin Transl Med 4: 6, 2015.

11. Kim YN, Koo KH, Sung JY, Yun UJ and Kim H: Anoikis resistance: An essential prerequisite for tumor metastasis. Int J Cell Biol 2012: 306879, 2012.
12. Iwatsuki M, Mimori K, Yokobori T, Ishi H, Beppu T, Nakamori S, Baba $\mathrm{H}$ and Mori M: Epithelial-mesenchymal transition in cancer development and its clinical significance. Cancer Sci 101: 293-299, 2010.

13. Chaffer CL, Thompson EW and Williams ED: Mesenchymal to epithelial transition in development and disease. Cells Tissues Organs 185: 7-19, 2007.

14. Yang J and Weinberg RA: Epithelial-mesenchymal transition: At the crossroads of development and tumor metastasis. Dev Cell 14: 818-829, 2008.

15. Yap AS, Brieher WM and Gumbiner BM: Molecular and functional analysis of cadherin-based adherens junctions. Annu Rev Cell Dev Biol 13: 119-146, 1997.

16. Nelson WJ: Remodeling epithelial cell organization: Transitions between front-rear and apical-basal polarity. Cold Spring Harb Perspect Biol 1: a000513, 2009.

17. Greenburg G and Hay ED: Cytoskeleton and thyroglobulin expression change during transformation of thyroid epithelium to mesenchyme-like cells. Development 102: 605-622, 1988.

18. Thiery JP, Acloque H, Huang RY and Nieto MA: Epithelial-mesenchymal transitions in development and disease. Cell 139: 871-890, 2009.

19. Kiesslich T, Pichler M and Neureiter D: Epigenetic control of epithelial-mesenchymal-transition in human cancer. Mol Clin Oncol 1: 3-11, 2013.

20. Radisky DC, Kenny PA and Bissell MJ: Fibrosis and cancer: Do myofibroblasts come also from epithelial cells via EMT? J Cell Biochem 10: 830-839, 2007.

21. Zeisberg EM, Tarnavski O, Zeisberg M, Dorfman AL, McMullen JR, Gustafsson E, Chandraker A, Yuan X, Pu WT, Roberts $\mathrm{AB}$, et al: Endothelial-to-mesenchymal transition contributes to cardiac fibrosis. Nat Med 13: 952-961, 2007.

22. Zeisberg EM, Potenta SE, Sugimoto H,Zeisberg M and Kalluri R: Fibroblasts in kidney fibrosis emerge via endothelial-tomesenchymal transition. J Am Soc Nephrol 19: 2282-2287, 2008.

23. Strippoli R, Benedicto I, Pérez Lozano ML, Cerezo A, López-Cabrera M and del Pozo MA: Epithelial-to-mesenchymal transition of peritoneal mesothelial cells is regulated by an ERK/NF-kappaB/Snail1 pathway. Dis Model Mech 1: 264-274, 2008.

24. Boutet A, De Frutos CA, Maxwell PH, Mayol MJ, Romero J and Nieto MA: Snail activation disrupts tissue homeostasis and induces fibrosis in the adult kidney. EMBO J 25: 5603-5613, 2006.

25. Hanahan D and Weinberg RA: Hallmarks of cancer: The next generation. Cell 144: 646-674, 2011.

26. Yeung KT and Yang J: Epithelial-mesenchymal transition in tumor metastasis. Mol Oncol 11: 28-39, 2017.

27. Derksen PW, Liu X, Saridin F, van der Gulden $H$, Zevenhoven J, Evers B, van Beijnum JR, Griffioen AW, Vink J, Krimpenfort $\mathrm{P}$, et al: Somatic inactivation of E-cadherin and p53 in mice leads to metastatic lobular mammary carcinoma through induction of anoikis resistance and angiogenesis. Cancer Cell 10: 437-449, 2006.

28. Tsai JH and Yang J: Epithelial-mesenchymal plasticity in carcinoma metastasis. Genes Dev 27: 2192-2206, 2013.

29. Jouppila-Mättö A, Tuhkanen H, Soini Y, Pukkila M, Närkiö-Mäkelä M, Sironen R, Virtanen I, Mannermaa A and Kosma VM: Transcription factor snaill expression and poor survival in pharyngeal squamous cell carcinoma. Histol Histopathol 26: 443-439, 2011.

30. Francí C, Gallén M, Alameda F, Baró T, Iglesias M, Virtanen I and García de Herreros A: Snaill protein in the stroma as a new putative prognosis marker for colon tumours. PLoS One 4: e5595, 2009.

31. Bièche I, Lerebours F, Tozlu S, Espie M, Marty M and Lidereau R: Molecular profiling of inflammatory breast cancer: Identification of a poor-prognosis gene expression signature. Clin Cancer Res 10: 6789-6795, 2004.

32. Sarkar FH, Li Y, Wang Z and Kong D: Pancreatic cancer stem cells and EMT in drug resistance and metastasis. Minerva Chir 64: 489-500, 2009.

33. van Zijl F, Zulehner G, Petz M, Schneller D, Kornauth C, Hau M, Machat G, Grubinger M, Huber H and Mikulits W: Epithelial-mesenchymal transition in hepatocellular carcinoma. Future Oncol 5: 1169-1179, 2009.

34. Halasova E, Adamkov M, Matakova T, Kavcova E, Poliacek I and Singliar A: Lung cancer incidence and survival in chromium exposed individuals with respect to expression of anti-apoptotic protein survivin and tumor suppressor P53 protein. Eur J Med Res 15 (Suppl 2): S55-S59, 2010. 
35. Heuberger $\mathbf{J}$ and Birchmeier W: Interplay of cadherin-mediated cell adhesion and canonical Wnt signaling. Cold Spring Harb Perspect Biol 2: a002915, 2010.

36. Katsuno Y, Lamouille $S$ and Derynck R: TGF- $\beta$ signaling and epithelial-mesenchymal transition in cancer progression. Curr Opin Oncol 25: 76-84, 2013.

37. Akhurst RJ and Padgett RW: Matters of context guide future research in TGF $\beta$ superfamily signaling. Sci Signal 8: re10, 2015.

38. Zavadil $\mathrm{J}$ and Böttinger EP: TGF-beta and epithelial-tomesenchymal transitions. Oncogene 24: 5764-5774, 2005.

39. Nawshad A, Lagamba D, Polad A and Hay ED: Transforming growth factor-beta signaling during epithelial-mesenchymal transformation: Implications for embryogenesis and tumor metastasis. Cells Tissues Organs 179: 11-23, 2005.

40. Ricciardi M, Zanotto M, Malpeli G, Bassi G, Perbellini O, Chilosi M, Bifari F and Krampera M: Epithelial-to-mesenchymal transition (EMT) induced by inflammatory priming elicits mesenchymal stromal cell-like immune-modulatory properties in cancer cells. Br J Cancer 112: 1067-1075, 2015.

41. Wei SC, Fattet L, Tsai JH, Guo Y, Pai VH, Majeski HE, Chen AC, Sah RL, Taylor SS, Engler AJ and Yang J: Matrix stiffness drives epithelial-mesenchymal transition and tumour metastasis through a TWIST1-G3BP2 mechanotransduction pathway. Nat Cell Biol 17: 678-688, 2015.

42. Roberts AB and Wakefield LM: The two faces of transforming growth factor beta in carcinogenesis. Proc Natl Acad Sci USA 100: 8621-8623, 2003

43. Cano A, Pérez-Moreno MA, Rodrigo I, Locascio A, Blanco MJ, del Barrio MG, Portillo F and Nieto MA: The transcription factor snail controls epithelial-mesenchymal transitions by repressing E-cadherin expression. Nat Cell Biol 2: 76-83, 2000.

44. Peinado H, Olmeda D and Cano A: Snail, Zeb and bHLH factors in tumour progression: An alliance against the epithelial phenotype? Nat Rev Cancer 7: 415-428, 2007.

45. Grille SJ, Bellacosa A, Upson J, Klein-Szanto AJ, van Roy F, Lee-Kwon W, Donowitz M, Tsichlis PN and Larue L: The protein kinase Akt induces epithelial mesenchymal transition and promotes enhanced motility and invasiveness of squamous cell carcinoma lines. Cancer Res 63: 2172-2178, 2003.

46. Zhang L, Huang G, Li X, Zhang Y, Jiang Y, Shen J, Liu J, Wang Q, Zhu J, Feng X, et al: Hypoxia induces epithelial-mesenchymal transition via activation of SNAI1 by hypoxia-inducible factor-1 $\alpha$ in hepatocellular carcinoma. BMC Cancer 13: 108, 2013.

47. Park SM, Gaur AB, Lengyel E and Peter ME: The miR-200 family determines the epithelial phenotype of cancer cells by targeting the E-cadherin repressors ZEB1 and ZEB2. Genes Dev 22: 894-907, 2008

48. Long J, Zuo D and Park M: Pc2-mediated sumoylation of Smad-interacting protein 1 attenuates transcriptional repression of E-cadherin. J Biol Chem 280: 35477-35489, 2005.

49. Xu J, Lamouille S and Derynck R: TGF-beta-induced epithelial to mesenchymal transition. Cell Res 19: 156-172, 2009.

50. Bax NA, Pijnappels DA, van Oorschot AA, Winter EM, de Vries AA, van Tuyn J, Braun J, Maas S, Schalij MJ, Atsma DE, et al: Epithelial-to-mesenchymal transformation alters electrical conductivity of human epicardial cells. J Cell Mol Med 15: 2675-2683, 2011.

51. Lamouille S, Xu J and Derynck R: Molecular mechanisms of epithelial-mesenchymal transition. Nat Rev Mol Cell Biol 15: 178-196, 2014

52. Yang MH, Hsu DS, Wang HW, Wang HJ, Lan HY, Yang WH Huang CH, Kao SY, Tzeng CH, Tai SK, et al: Bmil is essential in Twist1-induced epithelial-mesenchymal transition. Nat Cell Biol 12: 982-992, 2010

53. Li CW, Xia W, Huo L, Lim SO, Wu Y, Hsu JL, Chao CH Yamaguchi H, Yang NK, Ding Q, et al: Epithelial-mesenchymal transition induced by TNF- $\alpha$ requires NF- $\kappa \mathrm{B}$-mediated transcriptional upregulation of Twist1. Cancer Res 72: 1290-1300, 2012.

54. Cheng GZ, Zhang WZ, Sun M, Wang Q, Coppola D, Mansour M, $\mathrm{Xu}$ LM, Costanzo C, Cheng JQ and Wang LH: Twist is transcriptionally induced by activation of STAT3 and mediates STAT3 oncogenic function. J Biol Chem 283: 14665-14673, 2008.

55. Yang MH, Wu MZ, Chiou SH, Chen PM, Chang SY, Liu CJ, Teng SC and Wu KJ: Direct regulation of TWIST by HIF-1alpha promotes metastasis. Nat Cell Biol 10: 295-305, 2008.

56. Diepenbruck M and Christofori G: Epithelial-mesenchymal transition (EMT) and metastasis: Yes, no, maybe? Curr Opin Cell Biol 43: 7-13, 2016.
57. Porta-de-la-Riva M, Stanisavljevic J, Curto J, Francí C, Díaz VM, García de Herreros A and Baulida J: TFCP2c/LSF/LBP-1c is required for Snaill-induced fibronectin gene expression. Biochem J 435: 563-568, 2011.

58. Kuo YC, Su CH, Liu CY, Chen TH, Chen CP and Wang HS Transforming growth factor-beta induces CD44 cleavage that promotes migration of MDA-MB-435s cells through the up-regulation of membrane type 1-matrix metalloproteinase. Int J Cancer 124: 2568-2576, 2009.

59. Beaty BT and Condeelis J: Digging a little deeper: The stages of invadopodium formation and maturation. Eur J Cell Biol 93: 438-444, 2014

60. David JM and Rajasekaran AK: Dishonorable discharge: The oncogenic roles of cleaved E-cadherin fragments. Cancer Res 72: 2917-2923, 2012.

61. Kalluri R: EMT: When epithelial cells decide to become mesenchymal-like cells. J Clin Invest 119: 1417-1419, 2009.

62. Osta WA, Chen Y, Mikhitarian K, Mitas M, Salem M, Hannun YA, Cole DJ and Gillanders WE: EpCAM is overexpressed in breast cancer and is a potential target for breast cancer gene therapy. Cancer Res 64: 5818-5824, 2004.

63. Wu S, Liu S, Liu Z, Huang J, Pu X, Li J, Yang D, Deng H, Yang $\mathrm{N}$ and $\mathrm{Xu} \mathrm{J}$ : Classification of circulating tumor cells by epithelial-mesenchymal transition markers. PLoS One 10: e0123976, 2015.

64. Tam WL and Weinberg RA: The epigenetics of epithelialmesenchymal plasticity in cancer. Nat Med 19: 1438-1449, 2013.

65. Yoshikawa M, Hishikawa K, Marumo T and Fujita T: Inhibition of histone deacetylase activity suppresses epithelial-tomesenchymal transition induced by TGF-betal in human renal epithelial cells. J Am Soc Nephrol 18: 58-65, 2007.

66. Bullock MD, Sayan AE, Packham GK and Mirnezami AH: MicroRNAs: Critical regulators of epithelial to mesenchymal (EMT) and mesenchymal to epithelial transition (MET) in cancer progression. Biol Cell 104: 3-12, 2012.

67. Luo M, Li Z, Wang W, Zeng Y, Liu Z and Qiu J: Long non-coding RNA H19 increases bladder cancer metastasis by associating with EZH2 and inhibiting E-cadherin expression. Cancer Lett 333: 213-221, 2013.

68. Neureiter D, Zopf S, Leu T, Dietze O, Hauser-Kronberger C, Hahn EG, Herold C and Ocker M: Apoptosis, proliferation and differentiation patterns are influenced by Zebularine and SAHA in pancreatic cancer models. Scand J Gastroenterol 42: 103-116, 2007.

69. Richterová R, Jurečeková J, Evinová A, Kolarovszki B, Benčo M, De Riggo J, Sutovský J, Mahmood S, Račay P and Dobrota D: Most frequent molecular and immunohistochemical markers present in selected types of brain tumors. Gen Physiol Biophys 33: 259-279, 2014

70. Caplakova V, Babusikova E, Blahovcova E, Balharek T, Zelieskova $\mathrm{M}$ and Hatok J: DNA methylation machinery in the endometrium and endometrial cancer. Anticancer Res 36: 4407-4420, 2016.

71. Bolden JE, Peart MJ and Johnstone RW: Anticancer activities of histone deacetylase inhibitors. Nat Rev Drug Discov 5: 769-784, 2006.

72. Lapinska K, Housman G, Byler S, Heerboth S, Willbanks A, Oza A and Sarkar S: The effects of histone deacetylase inhibitor and calpain inhibitor combination therapies on ovarian cancer cells. Anticancer Res 36: 5731-5742, 2016.

73. Blahovcová E, Skovierová H, Strnádel J, Mištuna D and Halašová E: Apoptosis in cancer cells. In: Information technologies in medicine. Advances in intelligent systems and computing. Piętka E, Badura P, Kawa J and Wieclawek W (eds). vol. 472. Springer, Cham, pp207-213, 2016.

74. Shapiro IM, Cheng AW, Flytzanis NC, Balsamo M, Condeelis JS, Oktay MH, Burge CB and Gertler FB: An EMT-driven alternative splicing program occurs in human breast cancer and modulates cellular phenotype. PLoS Genet 7: e1002218, 2011.

75. Weidmann MD, Surve CR, Eddy RJ, Chen X, Gertler FB, Sharma VP and Condeelis JS: MenaINV dysregulates cortactin phosphorylation to promote invadopodium maturation. Sci Rep 6: 36142, 2016.

76. Brown RL, Reinke LM, Damerow MS, Perez D, Chodosh LA, Yang $\mathrm{J}$ and Cheng C: CD44 splice isoform switching in human and mouse epithelium is essential for epithelial-mesenchymal transition and breast cancer progression. J Clin Invest 121: 1064-1074, 2011.

77. Stefani G and Slack FJ: Small non-coding RNAs in animal development. Nat Rev Mol Cell Biol 9: 219-230, 2008 
78. Brabletz S and Brabletz T: The ZEB/miR-200 feedback loop-a motor of cellular plasticity in development and cancer? EMBO Rep 11: 670-677, 2010.

79. Burk U, Schubert J, Wellner U, Schmalhofer O, Vincan E, Spaderna $S$ and Brabletz T: A reciprocal repression between ZEB1 and members of the miR-200 family promotes EMT and invasion in cancer cells. EMBO Rep 9: 582-589, 2008.

80. Bracken CP, Li X Wright JA, Lawrence DM, Pillman KA, Salmanidis M, Anderson MA, Dredge BK, Gregory PA, Tsykin A, et al: Genome-wide identification of miR-200 targets reveals a regulatory network controlling cell invasion. EMBO J 33: 2040-2056, 2014.

81. Chang CJ, Chao CH, Xia W, Yang JY, Xiong Y, Li CW, Yu WH, Rehman SK, Hsu JL, Lee HH, et al: p53 regulates epithelial-mesenchymal transition and stem cell properties through modulating miRNAs. Nat Cell Biol 13: 317-323, 2011.

82. Brabletz S, Bajdak K, Meidhof S, Burk U, Niedermann G, Firat E, Wellner U, Dimmler A, Faller G, Schubert J and Brabletz T: The ZEB1/miR-200 feedback loop controls Notch signalling in cancer cells. EMBO J 30: 770-782, 2011.

83. Adamkov M, Halasova E, Rajcani J, Bencat M, Vybohova D, Rybarova $S$ and Galbavy S: Relation between expression pattern of p53 and survivin in cutaneous basal cell carcinomas. Med Sci Monit 17: BR74-BR80, 2011

84. Ma L, Young J, Prabhala H, Pan E, Mestdagh P, Muth D, Teruya-Feldstein J, Reinhardt F, Onder TT, Valastyan S, et al miR-9, a MYC/MYCN-activated microRNA, regulates E-cadherin and cancer metastasis. Nat Cell Biol 12: 247-256, 2010.

85. Ashworth TR: A case of cancer in which cells similar to those in the tumors were seen in the blood after death. Australasian Med J 14: 146-149, 1869.

86. Watanabe S: The metastasizability of tumor cells. Cancer 7 : 215-223, 1954

87. Watson MA, Ylagan LR, Trinkaus KM, Gillanders WE, Naughton MJ,Weilbaecher KN,Fleming TPand AftRL: Isolation and molecular profiling of bone marrow micrometastases identifies TWIST1 as a marker of early tumor relapse in breast cancer patients. Clin Cancer Res 13: 5001-5009, 2007.

88. Nierodzik ML, Plotkin A, Kajumo F and Karpatkin S: Thrombin stimulates tumor-platelet adhesion in vitro and metastasis in vivo. J Clin Invest 87: 229-236, 1991.

89. Kopp HG, Placke T and Salih HR: Platelet-derived transforming growth factor-beta down-regulates NKG2D thereby inhibiting natural killer cell antitumor reactivity. Cancer Res 69: 7775-7783, 2009.

90. Dasgupta A, Lim AR and Ghajar CM: Circulating and disseminated tumor cells: Harbingers or initiators of metastasis? Mol Oncol 11: 40-61, 2017.

91. Ao Z, Shah SH, Machlin LM, Parajuli R, Miller PC, Rawal S, Williams AJ, Cote RJ, Lippman ME, Datar RH and El-Ashry D Identification of cancer-associated fibroblasts in circulating blood from patients with metastatic breast cancer. Cancer Res 75: 4681-4687, 2015

92. Upreti M, Jamshidi-Parsian A, Koonce NA, Webber JS, Sharma SK, Asea AA, Mader MJ and Griffin RJ Tumor-endothelial cell three-dimensional spheroids: New aspects to enhance radiation and drug therapeutics. Transl Oncol 4: 365-376, 2011.

93. Sharma D, Brummel-Ziedins KE, Bouchard BA and Holmes CE: Platelets in tumor progression: A host factor that offers multiple potential targets in the treatment of cancer. J Cell Physiol 229: 1005-1015, 2014.

94. Cristofanilli M, Budd GT, Ellis MJ, Stopeck A, Matera J, Miller MC, Reuben JM, Doyle GV, Allard WJ, Terstappen LW and Hayes DF: Circulating tumor cells, disease progression, and survival in metastatic breast cancer. N Engl J Med 351: 781-791, 2004.

95. Goldkorn A, Ely B, Quinn DI, Tangen CM, Fink LM, $\mathrm{Xu}$ T, Twardowski P, Van Veldhuizen PJ, Agarwal N, Carducci MA, et al: Circulating tumor cell counts are prognostic of overall survival in SWOG S0421: A phase III trial of docetaxel with or without atrasentan for metastatic castration-resistant prostate cancer. J Clin Oncol 32: 1136-1142, 2014

96. Mego M, Cierna Z, Janega P, Karaba M, Minarik G, Benca J, Sedlácková T, Sieberova G, Gronesova P, Manasova D, et al Relationship between circulating tumor cells and epithelial to mesenchymal transition in early breast cancer. BMC Cancer 15 : 533,2015 .
97. Kasimir-Bauer S, Hoffmann O, Wallwiener D, Kimmig R and Fehm T: Expression of stem cell and epithelial-mesenchymal transition markers in primary breast cancer patients with circulating tumor cells. Breast Cancer Res 14: R15, 2012

98. Weismann P, Weismanova E, Masak L, Mlada K, Keder D, Ferancikova Z, Vizvaryova M, Konecny M, Zavodna K, Kausitz J, et al: The detection of circulating tumor cells expressing E6/E7 HR-HPV oncogenes in peripheral blood in cervical cancer patients after radical hysterectomy. Neoplasma 56: 230-238, 2009.

99. Mego M, Gao H, Lee BN, Cohen EN, Tin S, Giordano A Wu Q, Liu P, Nieto Y, Champlin RE, et al: Prognostic value of EMT-circulating tumor cells in metastatic breast cancer patients undergoing high-dose chemotherapy with autologous hematopoietic stem cell transplantation. J Cancer 3: 369-380, 2012.

100. Li YM, Xu SC, Li J, Han KQ, Pi HF, Zheng L, Zuo GH, Huang XB, Li HY, Zhao HZ, et al: Epithelial-mesenchymal transition markers expressed in circulating tumor cells in hepatocellular carcinoma patients with different stages of disease. Cell Death Dis 4: e831, 2013.

101. Jansson S, Bendahl PO, Larsson AM, Aaltonen KE and Rydén L: Prognostic impact of circulating tumor cell apoptosis and clusters in serial blood samples from patients with metastatic breast cancer in a prospective observational cohort. BMC Cancer 16: 433, 2016.

102. Chang MC, Chang YT, Chen JY, Jeng YM, Yang CY, Tien YW, Yang SH, Chen HL, Liang TY, Wang CF, et al: Clinical significance of circulating tumor microemboli as a prognostic marker in patients with pancreatic ductal adenocarcinoma. Clin Chem 62: 505-513, 2016.

103. Zhao Q, Barclay M, Hilkens J, Guo X, Barrow H, Rhodes JM and $\mathrm{Yu}$ LG: Interaction between circulating galectin-3 and cancer-associated MUC1 enhances tumour cell homotypic aggregation and prevents anoikis. Mol Cancer 9: 154,2010

104. Cheung KJ, Padmanaban V, Silvestri V, Schipper K, Cohen JD, Fairchild AN, Gorin MA, Verdone JE, Pienta KJ, Bader JS and Ewald AJ: Polyclonal breast cancer metastases arise from collective dissemination of keratin 14-expressing tumor cell clusters. Proc Natl Acad Sci USA 113: E854-E863, 2016.

105. Au SH, Storey BD, Moore JC, Tang Q, Chen YL, Javaid S, Sarioglu AF, Sullivan R, Madden MW, O'Keefe R, et al: Clusters of circulating tumor cells traverse capillary-sized vessels. Proc Natl Acad Sci USA 113: 4947-4952, 2016.

106. Cima I, Kong SL, Sengupta D, Tan IB, Phyo WM, Lee D, Hu M, Iliescu C, Alexander I, Goh WL, et al: Tumor-derived circulating endothelial cell clusters in colorectal cancer. Sci Transl Med 8: 345ra89, 2016.

107. Fabisiewicz A and Grzybowska E: CTC clusters in cancer progression and metastasis. Med Oncol 34: 12, 2017.

108. Punnoose EA, Atwal SK, Spoerke JM, Savage H, Pandita A, Yeh RF, Pirzkall A, Fine BM, Amler LC, Chen DS and Lackner MR: Molecular biomarker analyses using circulating tumor cells. PLoS One 5: e12517, 2010.

109. Zhang L, Ridgway LD, Wetzel MD, Ngo J, Yin W, Kumar D, Goodman JC, Groves MD and Marchetti D: The identification and characterization of breast cancer CTCs competent for brain metastasis. Sci Transl Med 5: 180ra48, 2013.

110. Chéry L, Lam HM, Coleman I, Lakely B, Coleman R, Larson S, Aguirre-Ghiso JA, Xia J, Gulati R, Nelson PS, et al: Characterization of single disseminated prostate cancer cells reveals tumor cell heterogeneity and identifies dormancy associated pathways. Oncotarget 5: 9939-9951, 2014.

111. Yu M, Bardia A, Wittner BS, Stott SL, Smas ME, Ting DT, Isakoff SJ, Ciciliano JC, Wells MN, Shah AM, et al: Circulating breast tumor cells exhibit dynamic changes in epithelial and mesenchymal composition. Science 339: 580-584, 2013.

112. Harouaka R, Kang Z, Zheng SY and Cao L: Circulating tumor cells: Advances in isolation and analysis, and challenges for clinical applications. Pharmacol Ther 141: 209-221, 2014.

113. Beije N, Jager A and Sleijfer S: Circulating tumor cell enumeration by the CellSearch system: The clinician's guide to breast cancer treatment? Cancer Treat Rev 41: 144-150, 2015.

114. Freidin MB, Tay A, Freydina DV, Chudasama D, Nicholson AG, Rice A, Anikin V and Lim E: An assessment of diagnostic performance of a filter-based antibody-independent peripheral blood circulating tumour cell capture paired with cytomorphologic criteria for the diagnosis of cancer. Lung Cancer 85: $182-185,2014$ 
115. Warkiani ME, Khoo BL, Wu L, Tay AK, Bhagat AA, Han J and Lim CT: Ultra-fast, label-free isolation of circulating tumor cells from blood using spiral microfluidics. Nat Protoc 11: 134-148, 2016.

116. Saucedo-Zeni N, Mewes S, Niestroj R, Gasiorowski L, Murawa D, Nowaczyk P, Tomasi T, Weber E, Dworacki G, Morgenthaler NG, et al: A novel method for the in vivo isolation of circulating tumor cells from peripheral blood of cancer patients using a functionalized and structured medical wire. Int J Oncol 41: 1241-1250, 2012.

117. Mani SA, Guo W, Liao MJ, Eaton EN, Ayyanan A, Zhou AY, Brooks M, Reinhard F, Zhang CC, Shipitsin M, et al: The epithelial-mesenchymal transition generates cells with properties of stem cells. Cell 133: 704-715, 2008.

118. Jolly MK, Jia D, Boareto M, Mani SA, Pienta KJ, Ben-Jacob E and Levine H: Coupling the modules of EMT and stemness: A tunable 'stemness window' model. Oncotarget 6: 25161-25174, 2015.

119. Jolly MK, Tripathi SC, Jia D, Mooney SM, Celiktas M, Hanash SM, Mani SA, Pienta KJ, Ben-Jacob E and Levine H: Stability of the hybrid epithelial/mesenchymal phenotype. Oncotarget 7: 27067-27084, 2016.

120. Damaskos C, Garmpis N, Valsami S, Kontos M, Spartalis E, Kalampokas T, Kalampokas E, Athanasiou A, Moris D, Daskalopoulou A, et al: Histone deacetylase inhibitors: An attractive therapeutic strategy against breast cancer. Anticancer Res 37: 35-46, 2017.

121. Škovierová H, Vidomanová E, Mahmood S, Sopková J, Drgová A, Cerveňová T, Halašová E and Lehotský J: The molecular and cellular effect of homocysteine metabolism imbalance on human health. Int J Mol Sci 17: 1733, 2016.

122. Stintzing S, Kemmerling R, Kiesslich T, Alinger B, Ocker M and Neureiter D: Myelodysplastic syndrome and histone deacetylase inhibitors: 'To be or not to be acetylated'? J Biomed Biotechnol 2011: 214143, 2011.
123. Li A, Liu Z, Li M, Zhou S, Xu Y, Xiao Y and Yang W: HDAC5, a potential therapeutic target and prognostic biomarker, promotes proliferation, invasion and migration in human breast cancer. Oncotarget 7: 37966-37978, 2016.

124. Stojanovic N, Hassan Z, Wirth M, Wenzel P, Beyer M, Schäfer C, Brand P, Kroemer A, Stauber RH, Schmid RM, et al: HDAC1 and HDAC2 integrate the expression of p53 mutants in pancreatic cancer. Oncogene 36: 1804-1815, 2017.

125. Mann BS, Johnson JR, He K, Sridhara R, Abraham S, Booth BP, Verbois L, Morse DE, Jee JM, Pope S, et al: Vorinostat for treatment of cutaneous manifestations of advanced primary cutaneous T-cell lymphoma. Clin Cancer Res 13: 2318-2322, 2007.

126. Marks PA: Discovery and development of SAHA as an anticancer agent. Oncogene 26: 1351-1356, 2007.

127. Barbarotta L and Hurley K: Romidepsin for the treatment of peripheral T-Cell lymphoma. J Adv Pract Oncol 6: 22-36, 2015.

128. Libby EN, Becker PS, Burwick N, Green DJ, Holmberg L and Bensinger WI: Panobinostat: A review of trial results and future prospects in multiple myeloma. Expert Rev Hematol 8: 9-18, 2015.

129. Ghajar CM: Metastasis prevention by targeting the dormant niche. Nat Rev Cancer 15: 238-247, 2015.

130. Marcucci F, Stassi G and De Maria R: Epithelial-mesenchymal transition: A new target in anticancer drug discovery. Nat Rev Drug Discov 15: 311-325, 2016.

This work is licensed under a Creative Commons Attribution-NonCommercial-NoDerivatives 4.0 International (CC BY-NC-ND 4.0) License. 